\title{
DISCOURSE AND COLLABORATION: THE ROLE OF CONVERSATIONS AND COLLECTIVE IDENTITY
}

\author{
CYNTHIA HARDY \\ University of Melbourne \\ THOMAS B. LAWRENCE \\ Simon Fraser University \\ DAVID GRANT \\ University of Sydney
}

\begin{abstract}
We explore the relationship between discourse and interorganizational collaboration, arguing that interorganizational collaboration can be understood as the product of sets of conversations that draw on existing discourses. Specifically, we argue that effective collaboration, which we define as cooperative, interorganizational action that produces innovative, synergistic solutions and balances divergent stakeholder concerns, emerges out of $\alpha$ two-stage process. In this process conversations produce discursive resources that create a collective identity and translate it into effective collaboration.
\end{abstract}

Organizations in all sectors of society increasingly are becoming involved in a variety of collaborative arrangements-alliances, partnerships, roundtables, networks, and consortia-in order to promote innovation, enter new markets, and deal with intractable social problems (Dyer \& Singh, 1998; Gray, 1989; Gulati, Nohria, \& Akbar, 2000; Powell, Koput, \& Smith-Doerr, 1996; Simonin, 1997). By collaborating, organizations hope to leverage the differences among them-in terms of knowledge, skills, and resources-so as to develop innovative, synergistic solutions to complex problems they cannot solve on their own (Bresser \& Harl, 1986; Gray, 1989; Gulati, 1999; Phillips, Lawrence, \& Hardy, 2000). Thus, in successful interorganizational collaborations, individual participants are able to draw on their organizational ties and, at the same time, transcend those ties to act collectively (Astley, 1984; Lawrence, Hardy, \& Phillips, 2002).

There is little agreement as to how to define collaboration; thus, a wide range of definitions exists. We define it as a cooperative, interorga-

We thank Dev Jennings and three anonymous reviewers for their insights and ideas on earlier versions of this article. We also acknowledge the financial support of the University of Melbourne. nizational relationship in which participants rely on neither market nor hierarchical mechanisms of control to gain cooperation from each other (Heide, 1994; Lawrence et al., 2002; Milne, Iyer, \& Gooding-Williams, 1996; Phillips et al., 2000; Powell, 1990). This definition encompasses a large variety of collaborative arrangements and distinguishes them from relationships that are cooperative but where cooperation is purchased, as in buyer-supplier relationships, or where it is based on the invocation of legitimate authority, as in cooperation between a state regulatory agency and an organization operating within its jurisdiction.

Although collaboration has the potential to produce powerful results, not all collaborations realize this potential. Many collaborations fail to produce innovative solutions or balance stakeholder concerns, and some even fail to generate any collective action whatsoever (Gray, 1989; Huxham, 1996; Lawrence et al., 2002). Consequently, researchers and managers alike are interested in identifying the factors and processes that lead to the accomplishment of effective collaboration, by which we mean collaboration that (1) leverages the differences among participants to produce innovative, synergistic solutions and (2) balances divergent stakeholder concerns. 
Effective collaboration among organizations is a difficult task; not only must cooperation and innovation be achieved, but the interests of those organizations represented in the collaboration must also be met. The challenge is even greater because cooperation among participants cannot be secured through market or hierarchical forms of control; although market or hierarchical concerns may prompt the formation of a collaboration, and all collaborations occur within the broad context of both markets and hierarchies, these mechanisms do not operate directly within the collaboration itself. Effective collaboration therefore depends on the relationships among participating members, which are negotiated on an ongoing basis throughout the life of the collaboration. Consequently, collaboration represents a complex set of ongoing communicative processes among individuals who act as members of both the collaboration and of the separate organizational hierarchies to which they are accountable.

In order to address these complexities and examine how effective collaboration can be achieved, we consider collaboration from a discursive perspective (Lawrence, Phillips, \& Hardy, 1999). This allows us to develop a model of interorganizational collaboration that relates effectiveness to the conversations among participants and to the wider discourse in which the collaboration takes place. In brief, our model suggests that effective collaboration results from a two-stage process in which participants engage in conversations that can include not only face-to-face dialogue but also a variety of other discursive practices, such as memos, letters, e-mails, and minutes of meetings (Ford \& Ford, 1995). The first stage of our model highlights the importance of a discursively constructed collective identity in the achievement of effective collaboration. The second stage of the model shows how this collective identity is translated through further conversations into innovative and synergistic action. Thus, by examining the discursive practices that constitute collaboration, we are able to explore the ways in which conversations can be managed to increase the likelihood of effective collaboration.

Adopting a discursive approach to the issue of effective collaboration provides a number of significant benefits. First, it directs attention to the communicative practices among participants, which are critical to effective collaboration, and, thus, provides a basis for practical insights into how conversations might be managed to increase the likelihood of effective collaboration. In this way, we build on other scholarly examinations of the role of language in effecting organized, collective action (Ford \& Ford, 1995; Heracleous \& Barrett, 2001; Palmer \& Dunford, 1996).

A second benefit of a discursive approach is that it highlights the processual and temporal aspects of collaboration, thus allowing us to view collaboration as a social accomplishment that occurs in an iterative fashion over time. The focus on language in use means that collaboration can be tracked more easily in a continuous fashion by following conversations on an ongoing basis, rather than trying to ascertain members' beliefs at discrete points in time.

Finally, a discursive approach facilitates the development of theory and research that attend to the multiple levels on which collaboration occurs; collaboration involves individual participants working in collaborative teams while representing the interests of organizational stakeholders. A discursive approach is attuned to the complex interrelationships among these levels and how they impact collaboration because it examines the conversations that occur within both the collaboration and the organization, and because it explores how the language used in conversations draws on discourses operating at organizational and societal levels (cf. Alvesson \& Körreman, 2002; Hardy \& Phillips, 1999).

We present our argument in four sections. First, we provide a theoretical overview of organizational discourse that highlights the role of conversations in generating discursive objects that represent resources for action. Second, we introduce the relationship between collective identity and collaboration and discuss the forms of conversation necessary for the production of a collective identity among organizational representatives in a collaboration. Third, we argue that collective identity alone is not sufficient to guarantee collaboration, and we explore the forms of conversation that provide the additional steps that translate identity into effective collaboration. We conclude with a consideration of the implications of our model for research and proctice. 


\section{ORGANIZATIONAL DISCOURSE}

In this section we provide an overview of key concepts from research on organizational discourse that underpin our model of effective collaboration. A discursive approach to organizational phenomena is more than a focus on language and its usage in organizations. It highlights the ways in which language constructs organizational reality, rather than simply reflects it (Gront, Keenoy, \& Oswick, 1998; Phillips \& Hardy, 2002). The study of discourse focuses on the ways in which actors drow on, reproduce, and transform discourses, and, in so doing, produce a social reality consisting of discursively constituted objects and ideas. Accordingly, research on organizational discourse examines the processes through which discursive objects are formed in organizations, the ways in which those objects constitute the social world, and the consequences of those discursive processes and objects for organizations.

Three concepts are critical to our discursive approach: discourse, text, and conversation. Although a wide variety of definitions have emerged across different disciplines (van Dijk, 1997), we define a discourse as a set of interrelated texts that, along with the related practices of text production, dissemination, and reception, bring an object or idea into being (Fairclough, 1992; Parker, 1992; Phillips \& Hardy, 1997). For example, the discourse of business strategy has produced a series of ideas, such as "core competence" and "strategic planning" (Knights \& Morgan, 1991), that have shaped business practice; the discourse of AIDS has established, in the developed world, the concept of a "patientactivist," which has led to various forms of active political opposition to governments and pharmaceutical companies (Maguire, Phillips, \& Hardy, 2001). Discourses therefore help to constitute a material reality by producing "identities, contexts, objects of value, and correct procedures" (Taylor, Cooren, Giroux, \& Robichaud, 1996: 28), which lead to particular practices through the way they shape what can be said and who can say it (Deetz, 1992; Fairclough, 1992).

Discourses are embodied in sets of texts that come in a wide variety of forms, including written documents, speech acts, pictures, and symbols (Gront et al., 1998; Taylor \& Van Every, 1993). At the same time, discourse has an existence beyond any individual text from which it is composed (Chalaby, 1996; Phillips, Lawrence, \& Hardy, 2004). Heracleous and Barrett describe the relationship between texts and discourse as analogous to that between action and social structure: "Just as the structural properties of social systems are, according to Giddens, instantiated as social practices, so the structural properties of discourse are instantiated in daily communicative actions" (2001: 758). The implication of this relationship is that researchers must examine sets of texts that describe and constitute organizational realities, as well as the complex relationships among texts and among discourses (Phillips \& Hardy, 2002).

One form that relationships among texts take, which is critical for this article, is that of a "conversation" (Taylor \& Van Every, 1993). We define a conversation as a set of texts that are produced as part of an interaction between two or more people and that are linked together both temporally and rhetorically (Ford \& Ford, 1995). Texts only exist as part of the same conversation if they are in some way responsive to each other, either directly or indirectly (a rhetorical connection), and are produced through chronologically sequenced discursive acts (a temporal connection). Conversations are important in understanding the role of language in organizations: consequential action is not so much the result of disconnected utterances or isolated texts but, rather, is produced through ongoing linguistic exchanges among actors that draw on broader discourses and produce discursive objects that act as resources for action and for further conversations (Fairclough, 1992). Thus, conversations exist in a recursive relationship in which existing discourses provide resources to actors who engage in conversations that in turn produce, reproduce, and transform those discourses (Taylor et al., 1996).

Ford and Ford (1995) argue that the forms of conversation associated with initiating organizational change are those that establish a need for change. From a discursive perspective, a "need for change," whether in the shape of an environmental shift, an organizational problem, or a political agenda, is a discursive object that, once produced, is available for use by other interested actors (Parker, 1992). In a collaborative context, individual participants might draw on a need for change in conversations both inside and outside the collaboration in order to 
justify resource allocations, motivate fellow participants and organizational colleagues, and legitimate decisions of inclusion and exclusion in the collaboration. As the need for change is drawn on in other conversations, it may become institutionalized in the discourse as one-or perhaps the only-legitimate way of talking about the issue.

These dynamics illustrate the potential politicality of conversation: conversations are at least partially the product of strategic action not only by elites but by a plurality of individuals involved in the production and consumption of texts (Grant et al., 1998). Moreover, discursive practices, including conversation, have the potential to produce significant political effects that result in the differential distribution of advantage among individuals and organizations (Fairclough, 1992; Mumby \& Clair, 1997).

In summary, we define a discourse as a set of interrelated texts and their related practices of consumption, production, and distribution, which bring into being an object or idea. The texts that populate discourses range from written works to speech acts to nonlinguistic symbols and images. Temporally and rhetorically related texts constitute conversations in which participants draw on and simultaneously produce discursive objects and ideas. Thus, a discursive approach to interorganizational collaboration is inherently processual and contextual (Lawrence et al., 1999): our focus on conversation highlights the processes through which collaboration is enacted over time; our interest in discourse ensures a concern for the broader context that provides the discursive objects that act as conversational resources for potential collaborators.

\section{COLLECTIVE IDENTITY}

In the remainder of this article, we explore the relationship between collective identity and effective collaboration and the role that discourse and conversations play in that relationship. Central to our argument is the idea that discursive processes produce collective identities, which lead to vorious forms of collective action, potentially including effective collaboration. In this section we discuss the fundamental role that collective identity plays in achieving collective action in the context of collaboration, and we then examine how collective identities are discursively formed through conversations in this context. In the following section we examine the conversations that affect the likelihood that collective identity will lead to effective collaboration (see Figure 1 for an overview of the model). We discuss these two sets of dynamics sequentially, but do not imply some sort of lock-step process; we separate them for analytic purposes only, fully realizing they likely overlap in time and space.

\section{Collective Identity and Āction}

The idea of collective identity is grounded in a variety of traditional sociological concepts, ranging from Durkheim's "collective conscious" to Marx's "class consciousness." It "addresses the 'we-ness' of a group, stressing the similarities or shared attributes around which group members coalesce" (Cerulo, 1997: 386). In organizational research, collective identity predominantly has been explained as members' convergent beliefs about the central, enduring, and distinctive attributes of their organization (Albert \& Whetten, 1985). These beliefs affect the way in which members interpret and react to issues facing the organization (Dutton \& Dukerich, 1991; Gioia \& Thomas, 1996) by influencing the importance that members attach to them, whether or not they see these issues as a threat or opportunity, and whether they are willing to invest time and energy in addressing them (Elsbach \& Kramer, 1996; Gioia \& Thomas, 1996). Some writers argue that convergence around collective identity leads to action by increasing organizational commitment (Ashforth \& Mael, 1989; Dutton et al., 1994) and strengthening organizational culture, motivating employees to work cooperatively (Fiol, 1991; Saffold, 1988; Schein, 1986). More recent work, however, highlights the importance of tensions, fluidity, and paradox in organizational identity (Fiol, 2002; Gioia, Schultz, \& Corley, 2000; Pratt \& Foreman, 2000).

We adopt a discursive perspective, which builds on recent interest in the tensions and fluidity associated with collective identity. From a discursive perspective, a collective identity exists as a discursive object produced in and through conversations, rather than as a cognitively held belief (Taylor \& Van Every, 1993). When collaborating partners discursively produce a collective identity, they produce a discur- 


\section{FIGURE 1}

A Model of Collective Identity, Conversations, and Effective Interorganizational Collaboration

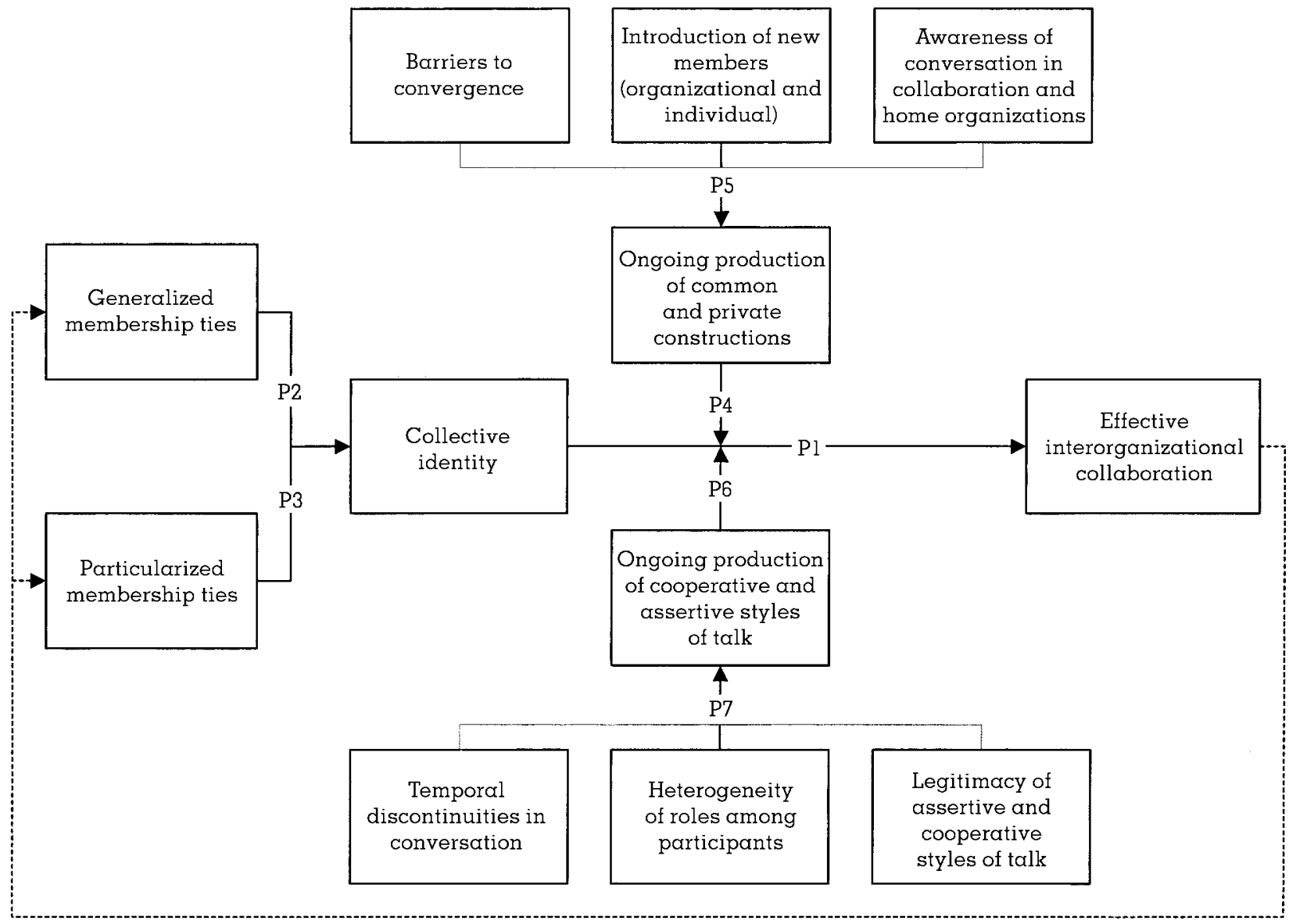

sive object that refers to themselves as some form of collective, rather than as simply a set of disconnected individuals or as a group of organizational representatives. This collective identity "names" the group-it gives it an identity that is meaningful to its members and to its stakeholders-and is shared, in the sense that members collectively engage in the discursive practices that produce and reproduce it over time. Thus, our focus is on collective identity as a linguistically produced object embodied in talk and other forms of text, rather than as a set of beliefs held in members' minds.

Discourse-oriented studies of collective identity concentrate on the processes through which a collective identity is produced via the creation of texts, and on the relationship of collective identity as a discursive object to patterns of action. Unlike research on social identity (e.g., Abrams \& Hogg, 1999; Ashforth \& Mael, 1989;
Hogg, 2000; Tajfel, 1972), a discursive approach does not examine what members are thinking, nor does it attempt to relate collective identity to individual social identities. Rather, its focus is primarily on the constructive effects of conversations in which participants describe themselves as a collective. A discursive conceptualization of collective identity provides a powerful basis for understanding the dynamics of collaboration, because it situates collective identity in the language in use among members and avoids the need to assess the degree of convergence across the minds of individuals. It shifts attention from the intentions and attitudes of individuals to their observable linguistic practices and the effects of those practices on social relationships and action (Potter \& Wetherell, 1987).

We argue that a collective identity, understood as a discursive object, is critically impor- 
tant in achieving effective collaboration. The discursive construction of a collective identity enables participants to construct themselves, the problem, and the solution as part of a collaborative framework in which the potential for joint action is both significant and beneficial. A collective identity also acts as a resource for participants in future conversations-to address, for example, internal conflict among members or differences in organizational interests that might otherwise jeopardize the collaboration. It helps individual participants in the collaboration attach importance to an issue, collectively invest time and energy in it, commit to any compromises involved in tackling it, take collective risks, and secure support from their respective organizations. A collective identity is particularly important in the case of collaboration, because the absence of market and hierarchical controls among participants means that they cannot rely on monetary exchange or hierarchical authority to achieve cooperation. Thus, the discursive construction of a collective identity through conversations can help participants in a collaboration identify with their partners and provide a rationale for the cooperation that is essential to its effectiveness (Gheradi, 1995). This relationship between collective identity and effective collaboration leads to our first proposition.

\section{Proposition 1: Effective interorganiza- tional collaboration will be more likely to ensue when the participants in a collaboration discursively pro- duce a collective identity for them- selves.}

\section{Conversations and Collective Identity}

Although a collective identity is critical to success, the complexities of interorganizational collaboration make the discursive construction of $a$ collective identity relatively difficult to achieve: whereas some notion of the central, enduring, and distinctive attributes of an organization can often be taken for granted (although perhaps in a minimal or problematic way), collaborations are often neither central (participants' home organizations continue to take priority) nor enduring (collaborations often have a fixed life span or lead a tenuous existence). It may also be difficult to develop distinctiveness when collab- orations take on a mixture of the attributes of participating organizations. At a minimum, interorganizational collaboration represents a complex arena in which to construct a collective identity, because it involves individual participants working together as a group while remaining connected to the organizations in which they work. This question thus arises: How is a collective identity produced in the case of collaboration?

Collins argues that collective identities are produced through conversations that discursively construct common "realities" regarding membership in different groups:

For example, shop talk involves membership in occupational groups, political and other ideological talk involves contending political coalitions, entertainment talk invokes groups with various tastes, general discussion invokes different intellectual and nonintellectual strata, while gossip and personal talk invoke specific and sometimes quite intimate memberships. Again, it is not important whether what is said is true or not, but whether it can be said and accepted as a common reality for that moment-that is what makes it on emblem of group membership (Collins, 1981: 9991000).

In the context of collaboration, this argument suggests that the types of conversations in which participants engage have a critical effect on the likelihood a collective identity will emerge.

Two specific types of conversations are particularly critical to the production of a collective identity within a collaboration: (1) those conversations that produce generalized membership ties-discursively constructed relationships that connect participants to a common issue around which the collaboration is organizedand (2) those conversations that produce particularized membership ties, which connect the participants directly to each other, rather than indirectly through on issue (Hardy, Lawrence, \& Phillips, 1998). Although we discuss these ties separately, conversations may involve an extensive network of connected exchanges, and, consequently, both generalized and particularized membership ties may be produced within the same conversations. Together, generalized membership ties and particularized membership ties provide the foundations for the discursive construction of a collective identity.

Generalized membership ties. Generalized membership ties revolve around membership in 
a community based on a connection to some issue or problem (Collins, 1981). These ties are produced through conversations that define an issue in a particular way and that connect organizations to that issue. Conversations that generate generalized membership ties provide a basis on which participants can identify on issue as relevant to their organizations and consequently identify themselves as interested in or affected by it.

The conversations that produce generalized membership ties are those in which issues are constructed, and so involve the production of accounts of the world as problematic and requiring action (Lawrence et al., 1999). Such conversations might be diagnostic, in that they define a problem and specify its causes; prognostic, in that they build consensus and mobilize action; or motivational, in the form of a general call to arms to potential participants and stakeholders (Benford \& Snow, 2000). The way in which an issue is constructed has important political effects on collaboration: it places limits on potential interactions and plays an important role in determining who has a legitimate case for membership in the collaboration (Gray, 1989; Gray \& Hay, 1986).

Some organizations will be more powerful than others in defining the issue (Altheide, 1988). We do not suggest that these actors necessarily enter into these conversations with fixed or predetermined views that they intend to "sell" (Dutton \& Ashford, 1993); rather, the discursive construction of issues often occurs in an emergent fashion as actors coproduce those constructions that affect the distribution of advantage and disadvantage, although in ways that were not necessarily intended or predicted.

At the same time, actors do not operate in a vacuum but in a larger discursive setting that shapes these conversations; only conversations that are sensible and legitimate within the context of prevailing discourses will produce generalized membership ties. For example, in the development of a collaboration between Canadian AIDS community groups and pharmaceutical firms to improve access to AIDS treatment (Maguire et al., 2001), community members drew strategically on scientific discourse. This preexisting discourse provided the means by which to construct generalized membership ties and allowed community members to connect to the issue of treatment as responsible and informed laypeople; however, it also constrained conversations-for example, by restricting incompatible talk of "irresponsible" activism.

Generalized membership ties play a critical role in the discursive production of a collective identity in the context of collaboration by facilitating participants' articulation of a shared issue as important to a number of stakeholders, including themselves, and as sufficiently enduring to warrant some form of collective response. For example, in a study of collaboration among employment service organizations, Hardy et al. (1998) found that only when conversations occurred that explicitly built generalized membership ties around a common issue were participants able to articulate an enduring rationale for a collaborative partnership and a collective vision of the future. Until then, a lack of generalized membership ties had impeded the production of a collective identity, despite monthly meetings over an eighteen-month period: forced together by their primary funder, and never having discussed who they were as a group or what their purpose was, participants had not clearly articulated an issue that located them as members of a larger domain. The relationship between generalized membership ties and collective identity leads to our next proposition.

Proposition 2: Participants in an inter-
organizational collaboration will be
more likely to discursively construct a
collective identity when they engage
in conversations that establish gener-
alized membership ties among them-
selves.

Particularized membership ties. The production of a collective identity depends on participants understanding themselves as tied to each other directly, as well as indirectly through the issue. Collins (1981) refers to ties that produce and reproduce direct relationships among conversational participants as particularized membership ties. These ties describe status, authority, and task-role relationships, as well as affiliative and collegial relations. In a collaboration, particularized membership ties involve routines, procedures, and structures that delineate, for instance, what roles individuals take in problem-solving or idea generation processes, who attends particular meetings, and, more formally, who can legitimately make decisions or 
speak on behalf of the collaboration (Gray, 1989; McConn, 1983).

The conversations that produce particularized membership ties are those that refer to specific persons, places, and objects and, consequently, provide a set of discursive resources from which participants can position themselves as connected in specific, identifiable ways. Gricar and Brown (1981), for example, describe collaborations as mapping relationships and interdependencies among member organizations, as well as coordinating activities among these stakeholders. Through these conversations, particularized membership ties are produced as certain stakeholders are included, patterns of interdependence are established, authority and status are conferred, and roles and responsibilities are assigned. In addition, the repeated nature of routine conversational activity-about particular matters, between particular people, in particular places-creates specific attachments and relationships (Collins, 1981; Taylor et al., 1996).

The discursive production of particularized membership ties is a political process: the inclusion (and exclusion) of particular organizations can be highly contentious and can significantly affect collaborative outcomes (Gray, 1985; Hardy \& Phillips, 1998). Participants with power may use it to exclude other stakeholders (Gricar \& Brown, 1981) in order to avoid "extreme" or "radical" views (Warren, Rose, \& Bergunder, 1974). In addition, who has authority, which procedures are invoked, and what particular coalitions are formed all have political implications, and, as such, participants may use power to influence particularized membership ties. At the same time, the larger discursive context constrains action; to be able to participate in a collaboration, participants need to occupy some legitimate position (Gray, 1985), but within any discourse, only a limited number of subject positions are understood as meaningful, legitimate, and powerful (Fairclough 1992; Foucault, 1972). Hence, inclusion or exclusion of certain groups, by virtue of whether they are legitimate participants in a collaboration or not, may largely be determined by broader discourses (Hardy \& Phillips, 1999).

The formation of particularized membership ties through conversation is an important precursor to the discursive production of a collective identity in the context of collaboration.
While generalized ties provide a substantive basis for the existence of a collective identity as stakeholders collectively face a particular issue, particularized ties provide a processual and structural basis for specific participants to address the issue in a particular forum. The collaboration in question is thus constructed as a real and distinct entity, separate and different from the organizations involved in it and more than simply a set of their representatives.

In a study of a collaboration between an aid organization located in the West Bank and a department of a Scandinavian university, Lawrence et al. (2002) found that the two organizations were able to discursively produce particularized ties to one another, despite significant cultural and sectoral differences between them, as a result of extensive conversations among their respective employees regarding the specifics of the project and their roles in it. These included operational and information meetings among employees of the two organizations, as well as a series of multiparty meetings that also involved government and nongovernmental organization (NGO) stakeholders. Through these processes, participants constructed themselves as closely and directly tied to each other. The relationship between particularized membership ties and collective identity leads to our next proposition.

Proposition 3: Participants in an interorganizational collaboration will be more likely to discursively construct a collective identity when they engage in conversations that establish particularized membership ties among them.

\section{CONVERSATIONS IN COLLABORATION}

The discursive construction of a collective identity may make collective action possible, but it does not necessarily lead to effective collaboration (cooperative, interorganizational action that produces innovative, synergistic solutions and balances divergent stakeholder concerns). We argue that collective identity is translated into effective collaboration through the impact of two other aspects of conversations. First is "constructions of key issues," by which we mean the ways in which central issues are defined in conversation. Second is "styles of 
talk" that characterize these conversationstheir tone, style, rhythm, and format. Each of these aspects of conversation makes important contributions to the process, but most critical to producing effective collaboration are the tensions, in the form of conflict and ambiguity, among different constructions and styles of talk.

\section{Constructions of Key Issues}

In collaborations, conversations must produce resources on which participants can draw to make sense of the situation and to create and legitimate courses of action. These discursive resources-understandings, frames of reference, and forms of knowledge, or, as we call them, "constructions"-are similar to Swidler's conception of culture as a "'tool kit'...from which actors select differing pieces for constructing lines of action" (1986: 277). Constructions provide a discursive tool kit from which participants can select and, having selected some constructions over others, engage in certain actions over others. A construction "rules in" certain ways of thinking about, talking about, and acting on a topic and "rules out" other ways (Hall, 2001: 72). In the process of collaboration, this occurs as the issue that has brought the collaborating partners together is described, examined, anclyzed, and acted on; these conversations discursively produce and maintain certain forms of knowledge, frames of reference, and understandings.

Our perspective on the construction of key issues is distinct from one in which the understanding of a problem is cognitive in nature; $a$ cognitive perspective might focus on "information" and the ways in which it is collected, shared, processed, and analyzed in order to determine the correct course of action (Huber, 1991). In contrast, from a discursive perspective, through conversations associated with the collaboration, individuals construct and legitimate particular knowledge, fromes of reference, and understandings, which, in turn, make certain actions meaningful and appropriate. Thus, the critical significance of constructions is their availability to participants to use as resources in further conversations (e.g., securing legitimacy and commitment for particular courses of action).

We argue that for effective collaboration to occur, two types of constructions must be estab- lished in participants' conversations: (1) common constructions of key issues and (2) private constructions of those same issues. As we discussed with generalized and particularized membership ties, these constructions may be produced in the same, overlapping, or different conversations. We treat them separately for theoretical clarity, but any empirical investigation would need to be attuned to this potential overlop.

Common constructions. In order for effective collaboration to occur, participants must engage in conversations that produce resources to make sense of the issue and related matters in terms on which there is general agreement. We call these discursive objects "common constructions." They occur when participants negotiate $a$ general agreement regarding the causes, symptoms, assumptions, and potential solutions that relate to the issue around which the collaboration is formed. These constructions are essential, because they allow participants to make sense of complex problems (Weick \& Roberts, 1993) and to communicate with each other well enough to coordinate collective action (Huxham, 1996). It is not enough to be connected to other participants and to the issue; participants must also establish a basis for communication if they are to reconcile their different interests and if synergy is to occur (Groy, 1989; Trist, 1983).

The production of common constructions is distinct from the establishment of the generalized membership ties that help to produce collective identity. Participants may engage in conversations that recognize their common interest in on issue without necessarily constructing it in the same terms. For example, union representatives and managers involved in wage negotiations may well produce generalized ties that connect them to a successful business. Through those negotiations they may even develop strong particularized ties that connect them to each other as negotiators. Accordingly, they may develop a collective identity around their joint roles in industrial bargaining. But they will not necessarily have a common construction of the problem: managers may construct wage increases as a threat to competitiveness, while union representatives may construct them as a redistribution of profits. In such a situation, it becomes difficult to produce a synergistic outcome; instead, the "solution" is more likely to be imposed, if one party proves more powerful, or 
to be a compromise, if not. While this form of action may be common in negotiations (Wells \& Liebman, 1996), it does not constitute effective collaboration.

Common constructions are necessary for effective collaboration, because communication among participants is contradictory and confusing without them. For example, in a study of interdepartmental collaboration associated with innovation, Dougherty (1996) found that different departments employed different meanings of the term market-oriented innovation. For $\mathrm{R} \& \mathrm{D}$, it meant product specifications and technical features-what the product could do. In manufacturing, it meant durability and reliability, which translated into fewer features and simpler specifications. Members in the planning department thought it meant having the product in the right market niche. Although these departments got together to collaborate and saw themselves as connected to the same issue, participants failed to produce a common construction of this issue. As a result, attempts to innovate failed, because the would-be innovators failed to bridge their different "thought worlds" through the articulation of common constructions, even though they engaged in conversations with each other and used the same terminology (Dougherty, 1996).

Private constructions. Effective collaboration also requires participants to engage in conversations that produce private constructions. In using this term, we are not referring to undisclosed constructions held by participants but, rather, constructions that are produced in ways that attach them to particular participants instead of the group as a whole. Thus, private constructions are discursive objects that lead individuals to make sense of and express key issues in disparate and often conflicting terms. In the context of interorganizational collaboration, they are often associated with the goals of the different organizations represented in the collaboration, but they might also involve a wide range of issues, such as appropriate technologies to employ, time frames for the collaboration, and stakeholder involvement.

Private constructions play a critical role in fostering creativity by juxtaposing "widely divergent bodies of knowledge and experience" (Fiol, 1995: 71), whereas conversations that involve only stable, shared knowledge inhibit the discovery of contrary experience from which in- novation arises (Jehn, 1997; Lovelace, Shapiro, \& Weingort, 2001). In other words, while common constructions facilitate communication and allow participants to create an atmosphere of mutual understanding, private constructions allow creativity and innovation (cf. Dougherty, 1996; Fiol, 1995). The value of diversity to innovation is a well-established idea in the collaboration literature, which often recommends bringing together individuals with different backgrounds to generate new ideas (e.g., Gray, 1989; Huxham, 1996), We suggest, however, that it is not the diversity of the collaborators per se that is the crucial element but, rather, the production of constructions of the issue that are clearly attached to particular participants.

The articulation of private constructions provides a set of discursive resources on which participants can draw as they attempt to negotiate solutions to the issue at hand. As such, private constructions play an important role in ensuring that the actions that emerge out of collaboration balance stakeholder interests, because they publicly commit participants to take into account the interests of the organizations they represent (Salancik, 1977) and because they help to ensure that the substantive issues preoccupying the organizations represented in the collaboration are present in the conversations among participants. In fact, private constructions are likely to be rooted in conversations that occur in participants' home organizations: as participants discuss the progress of the collaboration with their managers, private constructions will be produced, which then can be articulated in conversations among collaborators.

Effective collaboration is more likely to ensue if conversations produce both common and private constructions on an ongoing basis. Common constructions provide a basis for moving forward; private constructions facilitate the creation of the task-oriented conflict among participants necessary for innovation (Cosier \& Rose, 1977; Jehn, 1997). Private constructions are also an important way to ensure that stakeholder interests are not neglected through both public commitments and the inclusion of substantive concerns.

We argue that both sets of constructions need to be produced on an ongoing, rather than sequential, basis; this argument contrasts with the group development literature, which tends to 
suggest a period of divergence, such as brainstorming, followed by convergence prior to action (Katzenbach \& Smith, 1993; Mohrman, Cohen, \& Mohrman, 1995). Our argument for the ongoing juxtaposition of common and private constructions stems from the perspective that language does not represent or reveal the facts of the world but constructs them in conversation; thus, facts are not established once and for all but must continuously be reproduced if they are to be meaningful conversational elements that can affect the actions ensuing from the collaboration.

To summarize, effective collaboration is facilitated by a tension that stems from the ongoing circulation and interplay of common and private constructions and the ambiguities that result. While representational perspectives of language and communication "view ambiguity as a problem to be solved," a discursive approach "treats ambiguity as an opportunity to challenge, skirt, and reinvent received knowledge" (Eisenberg, 1998: 97). Thus, the innovation associated with effective collaboration is fueled by the ambiguity that emerges out of the simultaneous production of common and private constructions. These dynamics lead to our next proposition.

Proposition 4: The relationship between collective identity and effective collaboration will be strengthened by the maintenance of an ongoing tension between common and private constructions of key issues throughout the life of the collaboration.

Sustaining the production of both common and private constructions of key issues over the life of a collaboration is made difficult by people's preferences for coherence in conversation (Woodilla, 1998). A number of factors can mitigate this tendency toward convergence, however, and can facilitate the ongoing production of both sets of constructions. The first factor stems from the relationship between conversations that occur inside and those that occur outside the collaboration. We argue that the greater the awareness of the content of those conversations on both sides (participants are aware of other participants' conversations in their home organizations, and home organization managers are aware of the conversations within the collaboration), the more diverse the discursive resources available to all participants will be and the greater the motivation will be for participants to ensure that the tension between common and private constructions is maintained. This is not to say that, as the collaboration develops, there will be not particular moments where convergence occurs, allowing decisions to be made and coordinated action to be taken. However, thereafter, new issues will arise, and tension must again be created and maintained until convergence once again occurs.

The second factor stems from the impact of the composition of participants on the dynamics of conversations (Westley, 1990). We argue that the introduction of new members, in terms of either participating organizations or individual representatives, will be associated with both the introduction of new private constructions and the examination of the differences between common and private constructions; the conversations prompted by the arrival of new participants will, therefore, offset participants' tendencies toward convergence.

Finally, formal barriers to convergent language can be erected in the institution of collaborative practices, such as situations where participants are required to articulate private constructions for the purposes of creating conflict. These are not the only factors that influence the production of common and private constructions, but they represent three important factors, as indicated below.

Proposition 5: The ongoing production of common and private constructions in conversations will be facilitated by (a) mutual awareness of conversations across the collaboration and the representatives' home organizations, (b) the introduction of new members over time, and (c) barriers to convergence in the collaboration.

\section{Styles of Talk}

The second feature of conversations that moderates the relationship between collective identity and the likelihood of effective collaboration is the style of talk in which actors engage-the patterns in tone, style, rhythm, and format of conversations. Styles of talk are critical in collaboration because they provide the emotional 
energy necessary for participants to translate a collective identity into effective collaboration. The lack of market and hierarchical mechanisms of control among participants inherent in collaboration means that participants must generate their own motivation if they are to collaborate effectively. Different styles of talk generate this motivation in different ways and with different results. As with our discussion of the construction of key issues, it is not the utilization of a single style or even a combination of styles that is critical to the accomplishment of effective collaboration but, rather, the creation and maintenance of a tension among different styles of talk by participants.

We argue that effective collaboration involves an ongoing tension between two styles of talk in particular: (1) cooperative talk, which arises when the tone, style, rhythm, and format of conversations emphasize the willingness of participants to listen to and engage with each other's positions and interests, and (2) assertive talk, which occurs when the character of conversations emphasizes participants' insistence on articulating their own views and positions. In the remainder of this section, we explore the ways in which these two styles of talk influence the relationship between collective identity and the likelihood of effective collaboration, arguing that both forms are necessary for effective collaboration to occur.

Cooperative talk. Cooperative talk tends to occur in conversations that emphasize participants' similarity, mutual affiliations, and shared interests. This emphasis might be created through particular words chosen (or avoided), a tone that suggests mutual respect and consideration, or a structure in which all participants play an equal role (Atkinson \& Heritage, 1984; Psathas, 1995; Woodilla, 1998). By conducting conversations in this manner, participants associate the content of those conversations with a willingness to work with and accommodate each other's interests and preferences. This can occur even when the topic of conversation revolves around participants' private constructions and particular interests; through the tone, style, and format of their conversation, participants can signal accommodation and a willingness to compromise. Such cooperative talk underlies many normative models of collaboration:
In collaboration, problem-solving decisions are eventually taken by a group of stakeholders who have mutually authorized each other to reach a decision. Thus, power to define the problem and to propose a solution is effectively shared among the decision makers (Gray, 1989: 119).

Thus, through cooperative talk, action is generated collectively and inclusively. The adoption of such a style of talk ensures that communicative activity is shared and that meaning is coproduced by all participants, including less powerful partners. As Warren et al. point out, simply including diverse stakeholders is not enough to ensure effective collaboration, since there is always the risk that their voices will simply be "outweighed and outheard" (1974: 127). Cooperative talk works to ensure that the views of weaker organizational partners are incorporated, thereby enabling some form of shared purpose to emerge. It also helps participants to maintain their common constructions as central to the conversation and to integrate private constructions in a way that is more likely to produce the synergistic outcomes associated with effective collaboration (e.g., Lewis \& Weigert, 1985; Sabel, 1993). Moreover, cooperative talk tends to reinforce a group's collective identity-in signaling a willingness to cooperate, participants will draw on the collective identity as a discursive resource, talking in terms of "we" and "us," and recreating and revising identity in an ongoing manner.

A study of a collaboration between an NGO and a number of refugee organizations in the United Kingdom (Hardy \& Phillips, 1998) provides an example of the importance of cooperative talk among differentially powerful partners. This collaboration involved a considerable emphasis on cooperative talk, particularly on the part of the more powerful NGO, whose representatives were constantly questioning, "Should we be doing this or should we be helping a community organization to do it? You have to introduce that questioning so you don't automatically assume that you've got to do it" (collaborator quoted in Hardy \& Phillips, 1998: 222). Representatives of the NGO set great store on full participation by refugees as equal partners: "We don't usually impose things on [these] groups, we try to facilitate it" (collaborator quoted in Hardy \& Phillips, 1998: 222). Hardy and Phillips concluded that this collaboration was effective because of the way in which all partners-but particularly 
the more powerful participants-voluntarily and cooperatively participated in it, compared to other relationships that appeared to be collaborative on the surface but where neither participation nor power was shared.

Assertive talk. Assertive talk aids in effective collaboration by helping participants ensure that their organizational interests are represented in any action generated by the collaboration. Assertive talk energizes the differences among participants and provides a motivational basis for achieving synergistic, rather than simply compromising, outcomes. By engaging in assertive talk, individual participants attempt to influence the direction of conversations and frame the discussions that go on within them (Westley, 1990). As with cooperative talk, assertive talk can be produced through a conversation's tone (highly pitched, self-assured, insistent), style (aggressive, uncompromising), or structure (forceful turn-taking, free-for-all). It allows individual participants to discursively produce positions in which they are visibly and audibly affected by their personal and organizational stakes in the issue at hand. It also ensures that private constructions are articulated strongly and can be explored, promoted, and pursued; without assertive talk, private constructions are more likely to remain peripheral-stated, but not pushed forward for inclusion in collective sensemaking and decision-making processes. Moreover, assertive talk can be important in holding up common constructions to scrutiny, whereas cooperative talk tends to reinforce them. Since effective collaboration depends on innovation and creativity, the forceful promotion of private constructions and the critical examination of common constructions are both essential elements in this process.

Assertive talk is also important for the way in which it constructs participants' representational roles as legitimate and central aspects of the process. In engaging in assertive talk, participants demonstrate their commitment to the proprietary interests of the organizations they represent. This can smooth what has been described in collaboration research as the "twotable problem" (Gray, 1989), where participants are perceived as overly identified with the collaboration rather than the organization in which they work. Consequently, assertive talk can increase the degree to which home organization managers perceive that their representatives are committed to organizational interests. As a result, they will be more likely to continue their support for collaboration, which, in turn, will motivate participants to contribute to the conversations instead of the reverse-wondering whether their organization is likely to pull out of the collaboration, which makes it difficult for participants to sustain energy (cf. Westley, 1990).

The danger that stems from lack of assertive talk is illustrated in Westley and Vredenburg's (1991) study of a collaboration between a supermarket chain and an environmental organization in Canada to develop a new line of environmentally friendly products. The two CEOs engaged in highly cooperative talk and supported a common construction of the challenge-the importance of environmental groups and business working together. This cooperative talk was not, however, complemented with assertive talk, since the CEO of the environmental organization attempted to "streamline" meetings and to constrain the opportunity for other participants in the collaboration to engage in assertive talk. This made it difficult for dissenting employees to promote or defend private constructions of the issues, and it reduced the degree to which the interests of outside stakeholders were considered. As a result, the collaboration failed to produce innovative outcomes, lost the support of the board of the environmental organization, and was publicly condemned by other high-profile environmental groups.

We argue that a combination of cooperative and assertive talk will have a positively moderating effect on the relationship between collective identity and effective collaboration. Cooperative talk facilitates the leveraging of common constructions and the integration of private constructions, both of which engender collective action. Assertive talk ensures that private constructions are advanced, organizational responsibilities are acknowledged, and common constructions are critically challenged, all of which help to produce innovation and ensure that stakeholder interests are represented. Most critically, effective collaboration is driven by an ongoing interplay of both styles of talk and will emerge from situations in which agreement is regularly challenged and where styles of talk vary over time and across conversations in a fluid and potentially unpredictable manner.

Each style of talk plays a critical role in the accomplishment of effective collaboration, and 
neither can be suspended or set aside. They need not always feature together in an individual conversation, but they will have the greatest impact if both are interwoven over the life of the collaboration. In summary, a tension between the styles of talk helps to promote innovation and synergy and to ensure that stakeholder interests are represented. These dynamics lead to our next proposition.

Proposition 6: The relationship between collective identity and effective collaboration will be strengthened by the maintenance of an ongoing tension between assertive and cooperative styles of talk throughout the life of the collaboration.

The ongoing production of both cooperative and assertive talk may be difficult to achieve because of the potentially self-reinforcing aspects of each style of talk: norms of reciprocity suggest that cooperative talk on the part of one participant is likely to engender cooperative talk by others; similarly, assertive talk is likely to be met with equally assertive talk (Andersson \& Pearson, 1999). Thus, factors that increase the ongoing production of both styles of talk will be those that mitigate these self-reinforcing tendencies.

One such factor is the legitimacy of both styles of talk within the collaboration. This might be affected by direct discussions of the issue within the collaboration (as might be prompted by a skilled facilitator) or by the broader discursive context surrounding the collaboration (with different sectors and industries having distinct norms that might challenge or privilege one style of talk or another). A second factor concerns the diversity of roles or identities that participants take on. From a discursive perspective, different identities are associated with different legitimated vocabularies and conversational styles (Fowler, 1991; Iedema, 1998). By ensuring a heterogeneity of roles for participants within the collaboration, a single dominant style of talk is less likely to emerge. Finally, collaborative practices such as the pacing of conversations can help sustain both cooperative and assertive talk. Styles of talk are more likely to be self-reinforcing within the context of continuous conversations; consequently, the more often conversations are broken up, the greater the opportunity will be for participants to change the dominant style of talk and switch to the alternative form.

Proposition 7: The ongoing production of cooperative and assertive styles of talk will be facilitated by (a) legitimation of both styles of talk within the collaboration, (b) heterogeneity of roles among participants, and (c) temporal discontinuities in conversation.

The penultimate point to make about our model concerns the various feedback loops that exist among the concepts we have discussed. First, the relationship between generalized and particularized ties and common constructions is complex. Common constructions are distinct from membership ties, although both can be resources for the production of common constructions: collaborators can draw on the connections to the issue and to each other as they elaborate the way in which they jointly construct the issue. At the same time, common constructions act as resources for the ongoing discursive accomplishment of these ties, and, in fact, both ties and common constructions may be produced in the same conversations.

Second, styles of talk are also linked to membership ties in a reciprocal relationship. Generalized and particularized ties are resources for both styles of talk, depending on the emotional reaction to the issue and to the partners. For example, a passion for the issue (generalized) and respect for partners (particularized) are likely to produce cooperative talk, whereas a passion for the issue and a suspicion of partners may produce assertive talk. The style of talk also influences ties. For example, the predominance of cooperative talk may weaken generalized ties, but if, as a result, the participative process becomes more important than the end itself, particularized ties will strengthen. In contrast, the predominance of assertive talk may strengthen generalized ties but weaken particularized ties.

Finally, and more generally, to sustain effective collaboration, the processes underpinning the model must remain ongoing and successful-hence, the feedback loop shown between "effective interorganizational collaboration" and "generalized" and "particularized membership ties" in Figure 1. Any deviation or breakdown of these intricate processes would lead to the failure of the collaboration. Thus, we are 
suggesting in this model that the process of achieving effective collaboration may be a relatively fragile one.

\section{CONCLUSION}

We have developed a theory of effective collaboration that focuses on the roles of collective identity and conversation. Having defined effective collaboration as cooperative, interorganizational action that produces innovative, synergistic solutions and balances divergent stakeholder concerns, we adopted a discourse-oriented perspective that highlights the interaction of the discursive context, conversations among participants, and the discursive resources that are critical in achieving effective collaboration. We have argued that the discursive production of $a$ collective identity is on important step in producing effective collaboration and that it depends on the production of generalized and particularized membership ties. We have further argued that the relationship between collective identity and effective collaboration will be stronger to the extent that conversations among participants sustain on ongoing tension between common and private constructions and between cooperative and assertive styles of talk. This theory has important implications for research on collaboration and for the study of language in organizations more generally, as well as significant practical implications.

\section{Implications for Research}

The first implication is for research on the role of language in effective collaboration. Traditionally, studies of interorganizational collaboration have tended to privilege action at the expense of talk; effective collaboration has been associated with "getting things done" while avoiding "talk-fests." We believe in the importance of action, but we focus on the way in which talk establishes the foundations for action in effective collaboration.

Our model suggests some specific directions for research on this relationship. Researchers interested in the role of language should focus on the discursive resources (generalized and particularized membership ties, collective identity, common and private constructions of key issues, and cooperative and assertive styles of talk) that are available and, especially, the ten- sions among them. Our discursive perspective also highlights the role of broader discourses in supporting and constraining conversations; future research might examine the impacts and dynamics of the particular discourses within which an interorganizational collaboration is enacted.

A second research implication concerns the role of stakeholders. Collaboration researchers have often adopted a social psychological perspective, focusing on group dynamics and the behavior of individuals within the collaboration, while giving the interactions between stakeholder and the collaboration rather less attention. Our model suggests that discourse-oriented studies can make an important contribution to our understanding of this relationship when the conversations between organizational members and their representatives on the collaboration are examined. Researchers could examine collaborative failures caused by the withdrawal of organizational support and identify the signals to which organizations react when assessing whether to continue their support. It is not clear whether organizational members respond more to formal texts, such as progress reports, or to informal conversations with representatives. Similarly, researchers could examine the symbols that reassure stakeholders that a collaboration is safe and productive and, consequently, worthy of continued support.

A third implication concerns the factors that facilitate the maintenance of the tensions between common and private constructions and between cooperative and assertive styles of talk. Although the tradeoff between participants' roles as collaborators and as stakeholder representatives has long been recognized in the collaboration literature (Gray, 1985, 1989), it is less clear how such a tradeoff can be managed effectively. We have identified specific ways of maintaining the tensions that produce effective collaboration. Thus, in future research scholars should pay close attention to such factors as barriers to convergence, introduction of new members, and transparency of conversations in stakeholder organizations (which affect the likelihood that a tension between common and private constructions will be maintained), as well as temporal discontinuities in the process, heterogeneity of participants, and the legitimacy of various styles of talk (which affect the participants' styles of talk). 
A fourth research implication stems from the methodological advantages associated with the adoption of a discursive perspective. Studies of discourse are strongly empirical because of the way in which discourse leaves "traces" (Taylor \& Van Every, 2000), meaning that the objects of analysis are observable instances of talk and text. Accordingly, proponents of a discursive approach view the social world as an ongoing accomplishment that is held precariously in place through discursive struggle, which allows us to view a collaboration as something that is always in the act of "becoming" (cf. Tsoukas \& Chia, 2002), rather than as a discrete entity. A discursive approach also allows us to examine the "levels" involved in collaboration without reifying them. Whereas traditional research has focused on the psychology of individual participants, the group dynamics of the collaboration team, or, less often, the stakeholders represented in the collaboration, a discursive approach allows us to conceptualize these interactions through conversations that embrace and interconnect all "levels."

A final implication is connected to the emerging focus on organizing, rather than organization (Weick, 1998), and the conceptualization of organizational change as a process of becoming (Tsoukas \& Chia, 2002). This perspective highlights the importance of developing theories that attend to the dynamic, ongoing nature of organizational processes. Our model has shown how the maintenance of ongoing tensions with respect to the constructions produced in conversation and styles of talk is connected to effective collaboration through the way in which these tensions balance the competing needs of participant and representative in an ongoing process. Similar tradeoffs exist in other organizational processes (e.g., interdepartmental collaboration, cross-functional project teams, or taskforces where the individual is both a member of a project team or taskforce and a representative of a department or unit). In fact, organizational membership generally is fraught with conflicting goals and the need to balance individualistic and collectivist inputs.

In line with this perspective, our model explicitly focuses on how discourse theory enables us to observe the means by which individuals maintain multiple conflicting constructions of key issues and styles of talk on an ongoing basis. In doing so, it shows how researchers might attend to a broader range of organizational issues by considering the tensions effected by the presence of alternative constructions and styles of talk. We believe that much is to be gained by developing a wider array of methods that can highlight primary patterns of interaction without submerging less dominant threads.

\section{Implications for Practice}

Our model has important practical implications for organizational actors attempting to develop effective collaborations. Participants first need to produce a collective identity through the establishment of both generalized and particularized membership ties. Practically speaking, the opening sequences of collaboration should involve conversations that connect the issue to potential participants and articulate specific connections between them. Generalized membership ties rely on the establishment and legitimation of a vocabulary from which participants can draw to explain their own and others' participation to each other and to their home organizations; particularized ties require discursive resources that can be used to describe and explain the relationships among participants.

Once a collective identity is discursively produced, collaborators need to shift the conversations toward the ongoing production of common and private constructions. Our analysis suggests that this can be facilitated by establishing formal procedures in the collaboration that focus on repeatedly articulating the concerns of managers in the home organization; by building structures into the home organizations, such as teams, whose focus is integrating the learning occurring in the collaboration; by rotating membership in terms of who represents the home organization and, where appropriate, by rotating or adding to the stakeholders represented in the collaboration; and by including in the collaboration process some formal joint analysis of the differences among participants' private constructions and between common and private constructions. These mechanisms help to maintain the salience of both common and private constructions, as well as help to maintain the distinction between them. More imaginative mechanisms might include role plays in which participants swap representational roles for a period of time and are encouraged to voice 
"strong" descriptions of others' private constructions.

Facilitating an ongoing tension between assertive and cooperative styles of talk over the life of a collaboration requires an array of different skills, structures, and processes (Schweiger, Sandberg, \& Ragan, 1986). At a minimum, the importance of this tension suggests the value of skilled facilitation that can engender cooperative styles of talk amidst conflict and can engender legitimate assertive talk despite a group's desire to "get along." The importance of this tension also suggests the need to legitimate both forms of talk among participants and, where possible, to embed that legitimacy in conversations outside as well as inside the collaboration. In addition-and given that different identities are associated with different legitimated vocabularies and conversational stylesensuring heterogeneous roles are assigned to and rotated among participants may help to prevent one form of talk from dominating. Finally, more use might be made of temporal discontinuities to engender a change in the style of talk, by a facilitator calling "time out" or by the deliberate pacing of the meeting schedule.

A final practical implication concerns the boundaries of when the model can and should be applied. Our intent has been to develop a theory that explains the role of discourse in producing effective collaboration. If organizational actors engage in the processes described here, they should increase their chances of achieving cooperation and innovation while also meeting their respective interests. However, not all organizations, and not all forms of collaboration, are so ambitious. A significant proportion of interorganizational relationships are not intended to achieve innovative solutions or balance stakeholder interests; organizational actors regularly enter into relationships that are aimed at negotiating stakes in some fixed pot of resources, rapidly solving some temporary problem, or simply gaining legitimacy in the eyes of a third party. In none of these cases would we suggest that actors engage in the processes described above. Our model shows how large an investment and commitment effective collaboration demands in terms of the ambiguity that participants and stakeholders have to tolerate, as well as the need for subsidiary sets of supporting conversations to be set up in home organizations. Such an investment is only worthwhile when the stakes are high, but when they are, managers and researchers would do well to listen to the talk of collaboration.

\section{REFERENCES}

Abrams, D., \& Hogg, M. A. (Eds.). 1999. Social identity and social cognition. Oxford: Blackwell.

Albert, S., \& Whetten, D. 1985. Organizational identity. Research in Organizational Behavior, 7: 263-295.

Altheide, D. L. 1988. Mediating cutbacks in human services: A case study in the negotiated order. Sociological Quarterly, 29: 339-355.

Alvesson, M., \& Körreman, D. 2000. Varieties of discourse: On the study of organizations through discourse analysis. Human Relations, 53: 1125-1149.

Andersson, L., \& Pearson, C. 1999. Tit for tat? The spiraling effect of incivility in the workplace. Academy of Management Review, 24: 452-471.

Ashforth, B. E., \& Mael, F. 1989. Social identity theory and the organization. Academy of Management Review, 14: 2039.

Astley, W. G. 1984. Toward an appreciation of collective strategy. Academy of Management Review, 9: 526-535.

Atkinson, J. M., \& Heritage, J. (Eds.). 1984. Structures of social action: Studies in conversation analysis. Cambridge: Cambridge University Press.

Benford, R. D., \& Snow, D. A. 2000. Framing processes and social movements: An overview and assessment. Annual Review of Sociology, 26: 611-639.

Bresser, R. K., \& Harl, J. E. 1986. Collective strategy: Vice or virtue? Academy of Management Review, 11: 408-427.

Cerulo, K. A. 1997. Identity construction: New issues, new directions. American Review of Sociology, 23: 385-409.

Chalaby, J. K. 1996. Beyond the prison-house of language: Discourse as a sociological concept. British Journal of Sociology, 47: 684-698.

Collins, R. 1981. On the microfoundations of macrosociology. American Journal of Sociology, 86: 984-1013.

Cosier, R., \& Rose, G. 1977. Cognitive conflict and goal conflict effects on task performance. Organizational Behavior and Human Performance, 19: 378-391.

Deetz, S. A. 1992. Democracy in an age of corporate colonization. Albany: State University of New York Press.

Dougherty, D. 1996. Organizing for innovation. In S. R. Clegg, C. Hardy, \& W. R. Nord (Eds.), Handbook of organization studies: 424-439. London: Sage.

Dutton, J. E., \& Ashford, S. J. 1993. Selling issues to top management. Academy of Management Review, 18: 387-428.

Dutton, J. E., Dukerich, J. M., \& Harquail, C. V. 1994. Organizational images and member identification. Administrative Science Quarterly, 39: 239-263.

Dyer, J., \& Singh, H. 1998. The relational view: Cooperative strategies and sources of interorganizational competi- 
tive advantage. Academy of Management Review, 23: 660-679.

Eisenberg, E. M. 1998. Flirting with meaning. Journal of Language and Social Psychology, 17: 97-108.

Elsbach, K. D., \& Kramer, R. M. 1996. Members' responses to organizational identity threats: Encountering and countering the Business Week ratings. Administrative Science Quarterly, 41: 442-476.

Fairclough, N. 1992. Discourse and social change. Cambridge: Polity Press.

Fiol, C. M. 1991. Managing culture as a competitive resource: An identity-based view of sustainable competitive advantage. Journal of Management, 17: 191-211.

Fiol, C. M. 1995. Thought worlds colliding: The role of contradiction in corporate innovation processes. Entrepreneurship Theory and Practice, 19: 71-90.

Fiol, C. M. 2002. Capitalizing on paradox: The role of language in transforming organizational identities. Organization Science, 13: 653-666.

Ford, J. D., \& Ford, L. W. 1995. The role of conversations in producing intentional change in organizations. Academy of Management Review, 20: 541-570.

Foucault, M. 1972. The archeology of knowledge. London: Routledge.

Fowler, R. 1991. Language in the news: Discourse and ideology in the press. London: Routledge.

Gheradi, S. 1995. Gender, symbolism and organizational cultures. London: Sage.

Gioia, D. A., Schultz, M., \& Corley, K. G. 2000. Organizational identity, image, and instability. Academy of Management Review, 25: 63-81.

Gioia, D. A., \& Thomas, J. B. 1996. Identity, image, and issue interpretation: Sensemaking during strategic change in academia. Administrative Science Quarterly, 41: 370403.

Grant, D., Keenoy, T., \& Oswick, C. 1998. Introduction: Organizational discourse: Of diversity, dichotomy and multidisciplinarity. In D. Grant, T. Keenoy, \& C. Oswick (Eds.), Discourse and organization: 1-14. London: Sage.

Gray, B. 1985. Conditions facilitating interorganizational collaboration. Human Relations, 38: 911-936.

Gray, B. 1989. Collaborating: Finding common ground for multiparty problems. San Francisco: Jossey-Bass.

Gray, B., \& Hay, T. M. 1986. Political limits to interorganizational consensus and change. Journal of Applied Behavioral Science, 22: 95-112.

Gricar, B., \& Brown, L. D. 1981. Conflict, power, and organization in a changing community. Human Relations, 34: 877-893.

Gulati, R. 1999. Network location and learning: The influence of network resources and firm capabilities on alliance formation. Strategic Management Journal, 20: 397-420.

Gulati, R., Nohria, N., \& Akbar, Z. 2000. Guest editors' introduction to the special issue: Strategic networks. Strategic Management Journal, 21: 203-215.
Hall, S. 2001. Foucault: Power, knowledge and discourse. In M. Wetherell, S. Yates, \& S. Taylor (Eds.), Discourse theory and practice: A reader: 72-81. London: Sage.

Hardy, C., Lawrence, T. B., \& Phillips, N. 1998. Talk and action: Conversations and narrative in interorganizational collaboration. In D. Grant, T. Keenoy, \& C. Oswick (Eds.), Discourse and organization: 65-83. London: Sage.

Hardy, C., \& Phillips, N. 1998. Strategies of engagement: Lessons from the critical examination of collaboration and conflict in an interorganizational domain. Organization Science, 9: 217-230.

Hardy, C., \& Phillips, N. 1999. No joking matter: Discursive struggle in the Canadian refugee system. Organization Studies, 20: 1-24.

Heide, J. 1994. Interorganizational governance in marketing channels. Journal of Marketing, 50: 40-51.

Heracleous, L., \& Barrett, M. 2001. Organizational change as discourse: Communicative actions and deep structures in the context of information technology implementation. Academy of Management Journal, 44: 755-778.

Hogg, M. A. 2000. Social identity and self-categorization processes in organizational contexts. Academy of Management Review, 25: 121-140.

Huber, G. 1991. Organizational learning: The contributing process and the literatures. Organization Science, 2: 88115.

Huxham, C. (Ed.). 1996. Creating collaborative advantage. London: Sage.

Iedema, R. A. M. 1998. Institutional responsibility and hidden meanings. Discourse and Society, 9: 481-500.

Jehn, K. A. 1997. A qualitative analysis of conflict types and dimensions in organizational groups. Administrative Science Quarterly, 42: 530-557.

Katzenbach, J. R., \& Smith, D. K. 1993. The wisdom of teams: Creating the high performance organization. Boston: Harvard Business School Press.

Knights, D., \& Morgan, G. 1991. Strategic discourse and subjectivity: Towards a critical analysis of corporate strategy in organizations. Organization Studies, 12: 251-273.

Lawrence, T. B., Hardy, C., \& Phillips, N. 2002. Institutional effects of interorganizational collaboration: The emergence of proto-institutions. Academy of Management Journal, 45: 281-290.

Lawrence, T. B., Phillips, N., \& Hardy, C. 1999. Watching whale-watching: A relational theory of organizational collaboration. Journal of Applied Behavioral Science, 35: 479-502.

Lewis, J. D., \& Weigert, A. 1985. Trust as a social reality. Social Forces, 43: 967-985.

Lovelace, K., Shapiro, D. L., \& Weingart, L. R. 2001. Maximizing cross-functional new product teams' innovativeness and constraint adherence: A conflict communications perspective. Academy of Management Journal, 44: 779793.

Maguire, S., Phillips, N., \& Hardy, C. 2001. When "silence = death," keep talking: Trust, control and the discursive 
construction of identity in the Canadian HIV/AIDS treatment domain. Organization Studies, 22: 287-312.

McCann, J. E. 1983. Design guidelines for social problemsolving interventions. Journal of Applied Behavioral Science, 19: 177-189.

Milne, G. R., Iyer, E. S., \& Gooding-Williams, S. 1996. Environmental organization alliance relationships within and across nonprofit, business, and government sectors. Journal of Public Policy and Marketing, 15: 203-215.

Mohrman, S., Cohen, S., \& Mohrman, A. 1995. Designing team based organizations. San-Francisco: Jossey-Bass.

Mumby, D., \& Clair, R. P. 1997. Organizational discourse. In T. A. van Dijk (Ed.), Discourse as social interaction: 181205. London: Sage.

Palmer, I., \& Dunford, R. 1996. Conflicting uses of metaphors: Reconceptualizing their use in the field of organizational change. Academy of Management Review, 21: 691-717.

Parker, I. 1992. Discourse dynamics: Critical analysis for social and individual psychology. London: Routledge.

Phillips, N., \& Hardy, C. 1997. Managing multiple identity: Discourse, legitimacy and resources in the UK refugee system. Organization, 4: 159-185.

Phillips, N., \& Hardy, C. 2002. Discourse analysis: Investigating processes of social construction. Thousand Oaks, CA: Sage.

Phillips, N., Lawrence, T. B., \& Hardy, C. 2000. Interorganizational collaboration and the dynamics of institutional fields. Journal of Management Studies, 37: 23-43.

Phillips, N., Lawrence, T. B., \& Hardy, C. 2004. Discourse and institutions. Academy of Management Review, 29: 635652.

Potter, J., \& Wetherell, M. 1987. Discourse and social psychology: Beyond attitudes and behavior. London: Sage.

Powell, W. W. 1990. Neither market nor hierarchy: Network forms of organization. Research in Organizational Behavior, 12: 295-336.

Powell, W. W., Koput, K. W., \& Smith-Doerr, L. 1996. Interorganizational collaboration and the locus of innovation: Networks of learning in biotechnology. Administrative Science Quarterly, 41: 116-146.

Pratt, M. G., \& Foreman, P. O. 2000. Clarifying managerial responses to organizational identities. Academy of Management Review, 25: 18-42.

Psathas, G. 1995. Conversation analysis: The study of talk in interaction. London: Sage.

Sabel, C. F. 1993. Studies of trust: Building new forms of cooperation in a volatile economy. Human Relations, 46: 1133-1170.

Saffold, G. S., III. 1988. Culture traits, strength, and organizational performance. Academy of Management Review, 13: 546-558.

Salancik, G. R. 1977. Commitment and the control of organizational behavior and belief. In B. M. Staw \& G. R.
Salancik (Eds.), New directions in organizational behavior: 1-54. Chicago: St. Clair.

Schein, E. H. 1986. Organizational culture and leadership: $A$ dynamic view. San Francisco: Jossey-Bass.

Schweiger, D. M., Sandberg, W. R., \& Ragan, J. W. 1986. Group approaches for improving strategic decision making: $A$ comparative analysis of dialectical inquiry, devil's advocacy, and consensus. Academy of Management Journal, 29: 51-71.

Simonin, B. 1997. The importance of collaborative know-how: An empirical test of the learning organization. Academy of Management Journal, 40: 1150-1174.

Swidler, A. 1986. Culture in action: Symbols and strategies. American Sociological Review, 51: 273-286.

Tajfel, H. 1972. La categorisation sociale [Social categorization]. In S. Moscovici (Ed.), Introduction de la psychologie sociale, vol. 1: 272-302. Paris: Larousse.

Taylor, J. R., Cooren, F., Giroux, N., \& Robichaud, D. 1996. The communicational basis of organization: Between the conversation and the text. Communication Theory, 6: $1-39$.

Taylor, J. R., \& Van Every, E. J. 1993. The vulnerable fortress: Bureaucratic organization in the information age. Toronto: University of Toronto.

Trist, E. 1983. Referent organizations and the development of interorganizational domains. Human Relations, 36: 269284.

Tsoukas, H., \& Chia, R. 2002. On organizational becoming: Rethinking organizational change. Organization Science, 13: 567-582.

van Dijk, T. A. 1997. Discourse as interaction in society. In T. A. van Dijk (Ed.), Discourse as structure and process: 1-37. London: Sage.

Warren, R., Rose, S., \& Bergunder, A. 1974. The structure of urban reform. Lexington, MA: Heath.

Weick, K. E. 1998. Improvisation as a mindset for organizational analysis. Organization Science, 9: 543-555.

Weick, K. E., \& Roberts, K. H. 1993. Collective mind in organizations: Heedful interrelating on flight decks. Administrative Science Quarterly, 38: 357-381.

Wells, J. C., \& Liebman, W. B. 1996. New models of negotiation, dispute resolution, and joint problem solving. $\mathrm{Ne}$ gotiation Journal, 12: 119-136.

Westley, F. 1990. Middle managers and strategy: The microdynamics of inclusion. Strategic Management Journal, 11: 337-351.

Westley, F., \& Vredenburg, H. 1991. Strategic bridging: The collaboration between environmentalists and business in the marketing of green products. Journal of Applied Behavioral Science, 27: 65-90.

Woodilla, J. 1998. Workplace conversations: The text of organizing. In D. Grant, T. Keenoy, \& C. Oswick (Eds.), Discourse and organization: 31-50. Sage: London. 
Cynthia Hardy is professor of management in the Department of Management, University of Melbourne. She received her Ph.D. in organizational theory from Warwick University, UK. Her research interests include power, organizational discourse, and collaborative strategy. She is cofounder of the International Centre for Research on Organizational Discourse, Strategy and Change.

Thomas B. Lawrence is the Weyerhaeuser Professor of Change Management at Simon Fraser University in Vancouver, Canada. He received his Ph.D. in organizational analysis from the University of Alberta. His research focuses on the dynamics of power, change, and institutions in organizations and organizational fields.

David Grant is chair of organizational studies, The School of Business, University of Sydney. He received his Ph.D. from the London School of Economics and Political Science. His primary area of research interest is organizational discourse, especially where it relates to organizational change initiatives. 
Copyright of Academy of Management Review is the property of Academy of Management and its content may not be copied or emailed to multiple sites or posted to a listserv without the copyright holder's express written permission. However, users may print, download, or email articles for individual use. 